\title{
Gender segregation and the wage gap in Portugal: an analysis at the establishment level *
}

\author{
José A. Cabral Vieira \\ University of the Azores and CEEAplA \\ Ana Rute Cardoso \\ IZA Bonn, University of Minho, and CEPR ${ }^{\dagger}$ \\ Miguel Portela \\ Tinbergen Institute, NIPE-University of Minho, and IZA Bonn
}

February 2005

\begin{abstract}
Using a large linked employer-employee data set, this paper aims at quantifying the trend in worker segregation at the establishment level and its impact on wages in Portugal over a fifteen year period. We concentrate on the gender dimension, to answer the questions: What is the level of gender segregation across establishments in the Portuguese labor market and how has it evolved over time? What is the impact of segregation on wages? Is that impact different for men and women? Systematic and random components of segregation are computed. We use standard wage decomposition techniques to evaluate the impact of the composition of the labor force at the establishment level on wages. The results reveal a high degree of systematic gender segregation. A higher proportion of females in the establishment lowers females' wages while, on the contrary, it raises males' wages. The evidence gathered is consistent with the taste-based model of employer behavior and with the theory of sorting of workers across establishments based on their productivity.
\end{abstract}

KEYWORDS: systematic segregation; random segregation; gender; wage inequality.

JEL CODES: J31; D21; J7.

\footnotetext{
*This research was supported by Fundação para a Ciência e a Tecnologia and FEDER under the grants POCTI/ECO/33089/99 and, for the third author, SFRH/BD/5114/2001. We are grateful to Jacques Silber, Ken Troske, and four anonymous referees for comments on earlier versions of the paper, and to the Ministry of Employment, Department of Statistics, for access to the dataset used. The usual disclaimer applies.

${ }^{\dagger}$ Corresponding author: Ana Rute Cardoso, IZA, P.O. Box 7240, 53072 Bonn, Germany. E-mail: cardoso@iza.org
} 


\section{Introduction}

The composition of the labor force differs widely across employers. Two main lines of reasoning have been followed to explain that pattern: taste-based or quality-sorting recruitment. In the first case, preferences by employers (or co-workers or customers) will lead an employer into recruiting particular types of workers, but not others. Becker (1971) has set the stage for this analysis, under the heading discrimination in the labor market. The other line of reasoning distinguishes workers by their quality or productivity, to stress sorting effects, according to which similar workers will be matched together in firms, if their skills are complements in the production process. A good version of this type of models is presented in Kremer (1993) and Kremer and Maskin (1996). Both theories predict that workers with different attributes will be segregated into different workplaces.

Employment segregation will be a source of wage differentials between groups of workers to the extent that different firms pay different wages. The two theories mentioned diverge, however, on the implications of segregation for wage setting. Nevertheless, gender segregation along occupation or industry lines has been subject to wider scrutiny than gender segregation among establishments. Studies evaluating the impact of the degree of femaleness of the establishment on wages have in general found that inter-establishment gender segregation accounts for a substantial share of the wage gap (see Carrington and Troske (1995, 1998), Yoon et al (2003), Reilly and Wirjanto (1999), Groshen (1991), Pfeffer and Davis-Blake (1987) and, for earlier awareness on this pattern, McNulty (1967) and Buckley (1971)).

This paper aims at quantifying the trend in worker segregation across establishments and its impact on wages in Portugal over a fifteen year period. We concentrate on the gender dimension, to answer the questions: What is the level of gender segregation across establishments in the Portuguese labor market and how has it evolved over time? What is the impact of segregation on wages? Is that impact different for men and women? The aim is also to contribute to a better understanding of the Portuguese gender wage gap, which revealed a hump-shaped pattern from 1985 to 1999, reaching a peak in 1991.

The study relies on a large linked employer-employee data set gathered by the Ministry of Employment, based on an inquiry that every firm with wage-earners is legally obliged to fill in. Each year, an average of two million workers, 200 thousand establishments, and 150 thousand firms are covered.

We evaluate worker segregation across establishments as departures from the segregation that would prevail if workers were randomly assigned to establishments, instead of departures from perfect integration, if groups were proportionately represented in each establishment. In fact, Carrington and Troske (1997) have proven that, in particular in the presence of small units, different groups of workers will never be evenly distributed across establishments, even if the allocation is determined on a random basis. We therefore compute random and systematic segregation, using both the Gini and the dissimilarity indices. The impact of the degree of femaleness of the establishment on wages will be quantified using the Oaxaca and Cotton-Neumark procedures for wage decomposition.

The paper is organized as follows. Section 2 describes the data set. Section 3 provides information on the Portuguese labor market and describes trends in female employment. Section 4 analyzes systematic gender segregation across establishments, and section 5 discusses the impact of gender segregation on wages. Concluding comments are presented in section 6. 


\section{Data set}

The data used, Quadros de Pessoal, are gathered annually by the Ministry of Employment, based on an inquiry to every firm with wage-earners, which reports information on the firm, the establishment and all of its workforce. Given the legally binding nature of the inquiry, the response rate is extremely high. The fact that the information (namely on wages) is provided by the employer and the legal request for the data to be permanently displayed in a public space in the establishment, contribute to their reliability, reducing measurement errors. Reported data include the worker's gender, age, skill, occupation, schooling, tenure, earnings and duration of work, and the establishment's and the firm's location, industry, and size.

The full coverage of the workforce within establishments is a clear advantage of this data set for the study of worker segregation across establishments. Also, the data are very representative, being in fact a census of the establishments employing paid labor. A wide set of variables is reported for each worker, but nevertheless less rich information is provided on establishments.

Establishments in manufacturing and the services have been kept for analysis. Only wageearners aged 16 to 65 were considered. Note that a minimum establishment size requirement had to be imposed for the analysis of the homogeneity of the workforce within firms. Indeed, it would be meaningless to compute segregation for an establishment with one worker or a similarly tiny dimension. During the period under analysis, the legislation in the country defined a micro-firm as one employing less than 5 workers. We have considered that benchmark, and throughout the paper the analysis is restricted to establishments with at least 5 workers. Therefore, large and small firms - which may be different in terms of work organization and labor flexibility, for example - are included in the analysis, and just tiny ones have been dropped.

These criteria led to a data set of 1.4 million workers and 62 thousand establishments on average each year. A high proportion of the establishments in the Portuguese economy has less than 5 wage-earners, but nevertheless they employ a very small proportion of the workforce. Indeed, 90 percent of the wage-earners in the selected industries and age bracket is kept for analysis, even though just 40 percent of the establishments employing them fulfill the size requirement. ${ }^{1}$

\section{The Portuguese labor market and trends in female employment}

Interest in the Portuguese labor market has widened over the last two decades, mainly driven by its good performance after mid-1980s, when compared to other Western economies. For example, the unemployment rate declined from 9 percent in 1985 to 4 percent in 2000. The economy has been under a process of modernization and restructuring, mainly after joining the European Union in 1986.

As a consequence of this process of change, demand for skilled workers increased and overall wage inequality widened, as wages at the top of the distribution grew faster than those at the lower end (Cardoso, 1998). This has been associated with rising returns to education and job requirements, and is consistent with the skill-biased technological change hypothesis (see Hartog et al, 2001). In addition, wage differentials associated namely with firm size and industry affiliation are substantial when compared with other European countries (see for

${ }^{1}$ We have also considered establishments employing at least 3 workers, and performed the computation of the overall segregation index. The level of total segregation is slightly higher once those establishments are included in the analysis, whereas its trend is remarkably similar to the one that will be reported in section 4 . 
instance Hartog et al, 2000). In particular, the size of inter-industry wage dispersion is high, comparable to countries normally rated as having a decentralized wage setting system, such as the USA or Canada.

These large wage differences for apparently equally-skilled workers indicate flexibility to exploit industry or firm and establishment specific conditions, which may be related to particular circumstances regarding industrial relations. Indeed, high wage flexibility has been pointed out as a particular feature of this market (OECD, 1994), and studies at the micro level have shown that firms have considerable degree of freedom when manipulating wages, despite widespread collective bargaining (Cardoso and Portugal, 2005).

In addition, it is well-known that wages are in Portugal low compared to other Western economies. These lower wages reflect lower productivity of labor, which itself may indicate reduced levels of physical and human capital (see Branco and Mello, 1992).

Female participation in the labor market is high when compared to other Southern European countries such as Spain, Italy and Greece, and above the European Union average. Female employment has been steadily increasing in the Portuguese economy. Whereas it accounted for 32 percent of total employment in manufacturing and the services in 1985, by 1999 it had risen to 43 percent. The composition of female employment underwent changes as well. The share of employed women holding a University diploma increased during that period from 3 percent to 9 percent, while the share holding a High-School diploma increased from 11 percent to 19 percent. Changes in the composition of male employment have been slower, as the share of employed males holding a University diploma increased from 4 percent to 7 percent, and the share holding a High-School diploma increased from 11 percent to 16 percent. These values illustrate clearly the low level of educational attainment of the working population in Portugal.

Raw data points to a certain degree of gender segregation at the establishment level (see tables 4 and 5 in appendix). While in the sample of females the average share of women in the establishment is 56 percent to 65 percent, in the sample of males the values range from 20 percent to 25 percent - females tend to have predominantly female co-workers, and males tend to have predominantly male co-workers.

Economic growth and increasing integration of women into the labor market did not lead in Portugal to a systematic decline in the gender pay gap. In fact, the gap measured as the difference between the mean values of log-wages in each group increased from 1985 to 1991, declining afterwards. Furthermore, empirical evidence has shown that even after controlling for several worker and employer attributes, the Portuguese wage gap is significant and persistent (Kiker and Santos (1991), Vieira (1999)).

\section{Gender segregation at the establishment level: systematic and random com- ponents}

To evaluate total segregation in the labor force, the Gini and the Duncan dissimilarity indices, respectively $G$ and $D$, have been used.

$$
D=\sum_{i=1}^{T} \frac{1}{2}\left|w_{i}-m_{i}\right|
$$


where $w_{i}$ and $m_{i}$ are the establishment $i$ 's share of female and male employees in the sample, respectively, and $T$ is the number of establishments in the sample.

$$
G=1-\sum_{i=1}^{T} w_{i}\left(m_{i}+2 \sum_{j=i+1}^{T} m_{j}\right)
$$

with the calculation being performed in the data sorted by $w_{i} / m_{i}$. Both indices are bounded between 0 and 1, with 0 corresponding to maximum evenness (perfect integration), and 1 to maximum unevenness.

In intuitive terms, the value of the Duncan index indicates the share of men (or women) that would have to move to eliminate inter-firm segregation (see Carrington and Troske, 1995: 517). Thinking in terms of segregation curves, "the Gini index is equal to two times the area between the diagonal line and the segregation curve, while the dissimilarity index is equal to the maximum vertical distance between the diagonal and the segregation curve" (Hutchens, 2001: 17). For a more extensive discussion of the interpretation of the indices, see Flückiger and Silber (1999: 53-62).

Hutchens (2001) provides a thorough discussion of the properties of segregation indices. Out of seven desirable properties highlighted, the Gini index fails to meet additive decomposability (i.e. if we partition the population into mutually exclusive groups, the total Gini index cannot be exactly decomposed into the between-groups plus the within-groups components), whereas the dissimilarity index fails to meet the property relating to the movement of individuals between groups (for example, if women were shifted from a group with lower proportion of women to one with higher proportion of women, the dissimilarity index could nevertheless decrease). Hutchens himself does not attach much relevance to the problem of the Gini index, acknowledging that this is a useful measure. That is particularly so in our case, since we are not interested in knowing the contribution of a subset of establishments to total segregation. By verifying the remaining six properties, the Gini index allows for the ordering, in a credible way, of different distributions in terms of their level of segregation. The problem with the dissimilarity index is potentially more serious. However, that index has been extensively used in the previous literature (see for example Carrington and Troske (1995, 1997, 1998), or Yoon et al (2003)) and, if we want to have benchmark results to compare with ours, we are bound to use the same type of segregation indices. Or, as Hutchens acknowledges, "the dissimilarity index and the Gini index dominate the empirical literature" (Hutchens, 2001: 17) and we have therefore chosen to use them.

Segregation will never reach the value 0 , in particular if the economy is made up of small units, even if workers are randomly allocated to establishments. The example in Carrington and Troske (1998: 450-451) helps clarify this point: in an economy made up of a large number of two-worker establishments, whose labor force is assigned randomly from a population with an equal number of men and women, one would end up with one quarter of the establishments with two men, one quarter with two women, and half with one man and one woman. This would imply a Gini segregation index of 0.75 , and a Dissimilarity index of 0.5. A generalization of this result for different proportions of females in the labor force and different classes of establishment size is provided in Carrington and Troske (1998: 451) (1997: 403-404), showing that random allocation generates positive segregation as measured by traditional indices, and that reported segregation increases when the sample is made up of smaller establishments, therefore rendering comparisons across samples non-trivial.

One should therefore quantify the degree of systematic segregation existing in the sample evaluated as departures from random segregation (the one that would result from pure chance in the allocation of workers to establishments), instead of departures from absolute evenness. 
This idea was discussed and applied in Boisso et al (1994), as well as in Carrington and Troske (1997, 1998).

To compute random segregation, we consider the original number of females and males and the original establishment sizes in the sample. Then, workers are randomly reallocated to establishments and the segregation indices are computed. ${ }^{2}$ After a certain number of replications of this procedure, the average segregation index reached is the random segregation. To obtain the standard errors of the indices (total, random and systematic), we use the bootstrap technique applied to segregation measurement as explained in Boisso et al (1994) and later also applied by Carrington and Troske (1998). In our computations the bootstrap is based on 100 samples of 10 percent drawn from the original data. ${ }^{3}$

The systematic Gini segregation coefficient is computed as follows (Carrington and Troske, 1997):

$$
\hat{G}=\left\{\begin{array}{l}
\frac{G-G^{*}}{1-G^{*}} \text { if } G \geq G^{*} \\
\frac{G-G^{*}}{G^{*}} \text { if } G<G^{*},
\end{array},\right.
$$

where $\hat{G} \in[-1,1]$. If actual segregation exceeds random segregation $\left(G>G^{*}\right)$, then $\hat{G}$ quantifies excess segregation over that dictated by chance, expressed in percentage of the maximum segregation that could occur $\left(1-G^{*}\right)$. When $G<G^{*}$, we face a situation in which there is excess evenness (Carrington and Troske, 1997: 406) in the distribution of gender across establishments, that is, not even random allocation would be able to obtain that balance in the distribution of individuals. As this index assesses random deviation, its interpretation is not based on the quota of minorities nor on the size of the units. However, as the size of units increases, the modified segregation index, $\hat{G}$, tends toward the value of the original index, $G$. The same procedure applies to the dissimilarity index.

Gender segregation across establishments in the Portuguese labor market is high and has been relatively stable between 1985 and 1999 (see table 1). We observe a slight increase in the random segregation, which can be explained by the change in the dimension of establishments ${ }^{4}$ and in the female participation in the labor market.

Systematic segregation, when measured by the Gini coefficient, has been stable around 0.67 during this period. The Dissimilarity index reveals as well stability, around the value 0.49. This means that approximately 49 percent of women or men would have to switch employer to come to an equal (random) distribution of gender across establishments. This suggests a high level of segregation when compared to the USA manufacturing, since Carrington and Troske (1998) have reported values of 0.33 and 0.45 , respectively for the dissimilarity and the

${ }^{2}$ We use the uniform distribution to generate random numbers that sort workers, before they are matched to the original array of employers (keeping the original number of positions available in each employer). Using a random number generator, we guarantee that the reallocation does not follow a systematic pattern. The procedure used also guarantees that the data set has exactly the original structure (establishment size and gender composition of the workforce).

${ }^{3}$ We have repeated the procedure drawing 200 or 50 samples, and results remained roughly unchanged. We have also checked whether dealing with a sample of the workforce, as most authors are constrained to do, instead of the full population, would influence the results. Also in this case, results change very little. The full set of results is available from the authors upon request.

${ }^{4}$ The average establishment size in the population under study decreased from 28 to 20 workers over the period. 


\begin{tabular}{|l||c|c|c|c|c|c|c|c|}
\hline \multicolumn{1}{|c||}{} & \multicolumn{2}{c|}{ Total Segregation } & \multicolumn{2}{c|}{ Random Segregation } & \multicolumn{2}{c|}{ Systematic Segregation } & \\
\hline & dissimilarity & Gini & dissimilarity & Gini & dissimilarity & Gini & \\
\hline \hline 1985 & $0.553(0.016)$ & $0.732(0.016)$ & $0.121(0.005)$ & $0.190(0.007)$ & $0.492(0.017)$ & $0.670(0.019)$ & \\
1987 & $0.552(0.016)$ & $0.737(0.014)$ & $0.123(0.005)$ & $0.193(0.006)$ & $0.489(0.018)$ & $0.674(0.016)$ & \\
1989 & $0.556(0.016)$ & $0.739(0.012)$ & $0.126(0.004)$ & $0.197(0.006)$ & $0.491(0.017)$ & $0.674(0.014)$ & \\
1991 & $0.553(0.014)$ & $0.736(0.011)$ & $0.129(0.004)$ & $0.200(0.005)$ & $0.487(0.015)$ & $0.670(0.014)$ & \\
1993 & $0.548(0.012)$ & $0.733(0.012)$ & $0.135(0.004)$ & $0.210(0.005)$ & $0.478(0.012)$ & $0.662(0.014)$ & \\
1995 & $0.559(0.012)$ & $0.741(0.009)$ & $0.138(0.006)$ & $0.214(0.005)$ & $0.488(0.012)$ & $0.670(0.011)$ & \\
1997 & $0.564(0.009)$ & $0.744(0.010)$ & $0.141(0.004)$ & $0.218(0.005)$ & $0.493(0.010)$ & $0.672(0.013)$ & \\
1999 & $0.563(0.009)$ & $0.742(0.007)$ & $0.144(0.004)$ & $0.223(0.006)$ & $0.489(0.010)$ & $0.668(0.009)$ & \\
\hline
\end{tabular}

Table 1: Gender Segregation at the establishment Level. Note: Bootstrap standard errors in parentheses. Source: Computations based on Portugal, MSST (1985 to 1999).

Gini index. The values for Portugal are however remarkably in line with those presented for Korea by Yoon et al (2003), with an industry coverage similar to ours.

\section{The impact of gender segregation on wages}

To analyze the impact of gender segregation at the establishment level on wages, consider regressions of the type:

$$
W_{g i}=\beta_{g} X_{g i}+\eta_{g i}
$$

where subscript $g=(m, f)$ indicates the gender, $W_{g i}$ is the $\log$ hourly wage of worker $i, X_{g i}$ denotes a set of individual and job related characteristics, which includes the proportion of females in the establishment; $\beta_{g}$ denotes the regression coefficients and $\eta_{g i}$ is a random error term assumed to satisfy the usual properties. Hourly wages were computed as monthly wages divided by the number of hours worked. Tables 4 and 5 in appendix list all the variables included and their descriptive statistics.

From OLS estimation of equations (4) it follows that:

$$
\bar{W}_{m}-\bar{W}_{f}=\left(\bar{X}_{m}-\bar{X}_{f}\right) \hat{\beta}_{m}+\left(\hat{\beta}_{m}-\hat{\beta}_{f}\right) \bar{X}_{f}
$$

which is the Oaxaca (1973) male-based decomposition. The first term on the right hand side indicates the portion of the wage gap attributable to differences between sexes in the mean values of productive and job related characteristics (i.e. differences in endowments); the second term represents the portion attributable to differences in prices of those characteristics (often referred to as wage discrimination). The idea of the first term is to value the difference in endowments at the wage rate that would prevail in the economy in the absence of wage discrimination (the non-discriminatory wage structure, following the reasoning by Becker (1971)). Oaxaca suggested using alternatively male or female wages as that reference wage distribution, to define a range within which the values of the components would fall.

Cotton (1988) and Neumark (1988) choose instead the computation of a specific point within that range, by considering the non-discriminatory wage structure $\left(\hat{\beta}^{*}\right)$ as the weighted average of the female and male wage structures, with weights equal to their employment 
shares. The wage decomposition would therefore be defined as follows:

$$
\bar{W}_{m}-\bar{W}_{f}=\left(\bar{X}_{m}-\bar{X}_{f}\right) \hat{\beta}^{*}+\left(\hat{\beta}_{m}-\hat{\beta}^{*}\right) \bar{X}_{m}+\left(\hat{\beta}^{*}-\hat{\beta}_{f}\right) \bar{X}_{f}
$$

Differing from Oaxaca's proposal, the last two terms measure the male advantage and the female disadvantage in coefficients (i.e. the extent to which the returns to productive and other characteristics differ from the non-discriminatory returns). These two terms are then used as measures of the extent of labor market discrimination.

It therefore follows that the contribution of the proportion of female workers at the establishment level $(\mathrm{P})$ to the gender gap is given, under the Oaxaca method, by

$$
\left(\bar{P}_{m}-\bar{P}_{f}\right) \hat{\beta}_{m P}+\left(\hat{\beta}_{m P}-\hat{\beta}_{f P}\right) \bar{P}_{f}
$$

and by

$$
\left(\bar{P}_{m}-\bar{P}_{f}\right) \hat{\beta}^{*}+\left(\hat{\beta}_{m P}-\hat{\beta}^{*}\right) \bar{P}_{m}+\left(\hat{\beta}^{*}-\hat{\beta}_{f P}\right) \bar{P}_{f}
$$

under the Cotton-Neumark approach.

\subsection{Higher concentration of women in the establishment: lower wages for women, but higher for men}

The proportion of females in the establishment workforce has a negative impact on females' wages, with the coefficient being statistically different from zero in every year. Conversely, the higher the proportion of females in the establishment, the higher males' wages (except in 1999) (see tables 6 and 7 in appendix). For example, for males in 1985 an increase of 10 percentage points in the proportion of females in the establishment was associated with an increase of 0.3 percent in the average wage; this coefficient remained relatively stable over the sample period, with a slight decrease after 1995. On the other hand, the negative impact of this variable on female wages increased until early-90s; by 1993, a 10 percentage point increase in the proportion of females in the establishment was associated with a decline in average female wages of approximately 1 percent. These results contrast to previous available evidence that had revealed that the femaleness of the establishment depressed the wages of both men and women (see Carrington and Troske (1998) or Reilly and Wirjanto (1999)).

We have checked whether these results could be driven by the aggregate occupational controls used in the regressions. That is not the case, since results are very stable once we include more detailed controls (two- or three-digit classification of occupations). Moreover, the results are also invariant to the exclusion of part-timers from the regression. ${ }^{5}$

Still one other problem might affect the results. Even though the previous literature on this issue has relied on OLS estimation, the endogeneity of the variable share of females might bias the results. We have extensively searched for ways to account for the endogeneity of this variable. ${ }^{6}$ Omitted variables is the most likely source of bias in our OLS regressions. We would like to control for firm attributes that may be correlated with the share of females in its

${ }^{5}$ The full set of results is available from the authors upon request.

${ }^{6}$ First of all, we have searched for feasible instruments. The share of female in the occupation or in the region seemed at first sight natural candidates. However, the share of females in the occupation has been used in the literature as a direct determinant of individual wages (see for example Bayard et al, 2003), and the share of females at the regional level can itself be considered a determinant of the wage level of the worker. We concluded that we were unable to find in our dataset feasible instruments for the share of females in the establishment. 
establishments, but data limitations force us to include such variables in the error term. Firms may select the share of females they hire based on certain variables we are not controlling for. In particular, we have not controlled for the establishment productivity and it seems reasonable to assume that there are some unobserved productivity differentials captured in the error term of the regression that may be correlated with the share of females included in the equation. For instance, firms with low productivity might tend to employ more female workers because they fit the jobs better, and females might be less productive than males due for example to job career interruptions. If such a sorting process exists, it would show up in the regression coefficient of the share of females, since productivity is not controlled for.

We believe however that this selection issue can be tackled if we include a firm-specific effect in the wage regression. We have thus re-run the wage regressions including a set of firm dummy variables. These terms are bound to capture the heterogeneity across firms in terms of, for example, productivity, product market conditions or average labor quality. Controlling for firm unobservable attributes should, at least partly, account for productivity differences across establishments.

The results for these estimations are reported in tables 8 and 9 . The results for the male working population using fixed-effects are in line with the ones previously obtained. There is still a positive impact of the share of females in the establishment on male wages. Indeed, from 1985 to 1995 that effect is now much stronger than previously estimated. If the mechanism of sorting based on productivity described above were indeed at work, we would expect these results (since, without any kind of control for the firm productivity, the negative covariance between the share of females and the firm productivity would bias the coefficient on the share of females downwards ${ }^{7}$ ).

For the female working population, results from 1993 onwards using fixed-effects are consistent with the ones previously obtained using OLS, i.e. a larger share of females in the establishment lowers female wages. That effect is now stronger. However, from 1985 to 1991 we find using fixed effects that a larger share of female had a positive impact also on female wages (as opposed to the previous results using OLS). ${ }^{8}$

The taste-based wage discrimination and the quality-sorting theories reach different predictions regarding wage gaps. According to the sorting theory, the wages of different groups of workers within a firm will be positively correlated (see the matching models in Kremer (1993) and, for a more general model, Kremer and Maskin (1996)). The wage discrimination theory, on the other hand, allows for the wages of men working with women to be higher than the wages of other men, to compensate them for the 'disutility' of having female co-workers. The evidence that a higher proportion of females in the establishment lowers wages for women but raises wages for men would therefore lend support to wage discrimination type of models. However, comparison of the OLS results with the fixed-effects results highlights the relevance of sorting type of theories for the explanation of the pattern and trend of gender wage setting in Portugal.

Over time, the positive impact of the share of females at the establishment on male wages declined in Portugal. As the proportion of female workers in the economy increased, the

${ }^{7}$ With no control for firm productivity, we would have $E(\hat{b})=b+c \frac{\operatorname{Cov}(P, F)}{\operatorname{var}(P)}$, where $P$ stands for the proportion of females, $F$ is the firm productivity, $b$ is the coefficient on the proportion of females and $c$ is the coefficient on productivity, if it were observable and had been included in the regression. Since $c>0$ and $\operatorname{Cov}(P, F)<0$, the lack of control for productivity biases $b$ downwards.

${ }_{8}$ As expected, the coefficient on the size of the establishment is now considerably lower than before, since most of that effect is absorbed by the firm dummy variable. 
compensation that male workers seem to receive for working with females has declined. This result points to a fading out of discrimination mechanisms.

\subsection{Segregation and the wage gap}

We return to the OLS results previously used in the literature (and will comment below on the results of the fixed-effects model). The contribution of the concentration of females at the establishment level to the gender wage differential is quite significant, varying from 11 percent in 1985 and 1995 to 25 percent in 1989 (see the last column in table 2).

\begin{tabular}{|c|c|c|c|c|c|c|c|c|}
\hline \multirow[t]{2}{*}{ Method. } & \multicolumn{3}{|c|}{ Oaxaca (1973) } & \multicolumn{4}{|c|}{ Cotton (1988), Neumark (1988) } & \multirow[b]{2}{*}{$P f / g a p$} \\
\hline & endow. & prices & total & endow. & male adv. & fem. dis. & total & \\
\hline 1985 & & & & & & & & \\
\hline all var. & 0.1108 & 0.1465 & 0.2573 & 0.1112 & 0.0465 & 0.0997 & 0.2574 & \\
\hline Pf & -0.0108 & 0.0389 & 0.0281 & -0.0028 & 0.0044 & 0.0264 & 0.0281 & 10.9 \\
\hline 1987 & & & & & & & & \\
\hline all var. & 0.0944 & 0.1566 & 0.2510 & 0.0974 & 0.0486 & 0.1049 & 0.2510 & \\
\hline $\mathrm{Pf}$ & -0.0132 & 0.0524 & 0.0391 & -0.0021 & 0.0061 & 0.0351 & 0.0391 & 15.6 \\
\hline 1989 & & & & & & & & \\
\hline all var. & 0.0911 & 0.1787 & 0.2698 & 0.0992 & 0.0544 & 0.1162 & 0.2698 & \\
\hline Pf & -0.0113 & 0.0789 & 0.0675 & 0.0063 & 0.0099 & 0.0513 & 0.0675 & 25.0 \\
\hline 1991 & & & & & & & & \\
\hline all var. & 0.0952 & 0.1942 & 0.2894 & 0.1054 & 0.0617 & 0.1224 & 0.2894 & \\
\hline $\mathrm{Pf}$ & -0.017 & 0.0838 & 0.0668 & 0.0027 & 0.0114 & 0.0528 & 0.0668 & 23.1 \\
\hline 1993 & & & & & & & & \\
\hline all var. & 0.0911 & 0.1958 & 0.2869 & 0.1012 & 0.0643 & 0.1214 & 0.2869 & \\
\hline $\mathrm{Pf}$ & -0.0102 & 0.0782 & 0.0681 & 0.0085 & 0.0110 & 0.0485 & 0.0681 & 23.7 \\
\hline 1995 & & & & & & & & \\
\hline all var. & 0.1013 & 0.1630 & 0.2644 & 0.1046 & 0.0612 & 0.0985 & 0.2644 & \\
\hline $\mathrm{Pf}$ & -0.0137 & 0.0397 & 0.0260 & -0.0038 & 0.0059 & 0.0240 & 0.0260 & 9.9 \\
\hline 1997 & & & & & & & & \\
\hline all var. & 0.0943 & 0.1615 & 0.2558 & 0.0986 & 0.0619 & 0.0953 & 0.2558 & \\
\hline $\mathrm{Pf}$ & -0.0059 & 0.0479 & 0.0420 & 0.0064 & 0.0073 & 0.0283 & 0.0420 & 16.4 \\
\hline 1999 & & & & & & & & \\
\hline all var. & 0.0944 & 0.1641 & 0.2585 & 0.0990 & 0.0637 & 0.0958 & 0.2585 & \\
\hline $\mathrm{Pf}$ & 0.0051 & 0.0542 & 0.0593 & 0.0192 & 0.0085 & 0.0316 & 0.0593 & 23.0 \\
\hline
\end{tabular}

Table 2: Male/female LoG-Wage Decompositions. Source: Computations based on Portugal, MSST (1985 to 1999).

The role of prices has been prominent (see table 2). The Oaxaca methodology using male wages as the benchmark indicates that, concerning the proportion of females at the establishment level, the contribution of the endowment component is negative (except in 1999). In fact, given that the share of females has a positive impact on males wages (the reference wage distribution considered) and that women on average work in establishments 
with a higher proportion of females, the endowment component would raise female wages, reducing the gender wage gap. However, this is offset by the effect of differences in prices (i.e. coefficients) associated with the femaleness of the establishment (precisely because they are positive for men and negative for women, as previously reported). This price component accounts for 15 percent of the observed gap in 1985 and 21 percent in 1999, fluctuating during the period in-between.

\begin{tabular}{|r||r|r|r|r|r|r|r|r|r|r|}
\hline \multicolumn{1}{|c||}{} & \multicolumn{4}{c|}{ Oaxaca (1973) } & \multicolumn{4}{c|}{ Cotton (1988) and Neumark (1988) } \\
\hline & all variables & \multicolumn{1}{c|}{ prop. females } & \multicolumn{3}{c|}{ all variables } & \multicolumn{3}{|c|}{ prop. females } \\
\hline & end. & prices & end. & prices & end. & male ad. & fem. dis. & end. & male ad. & fem. dis. \\
\hline \hline 1985 & 43.1 & 56.9 & -4.2 & 15.1 & 43.2 & 18.1 & 38.7 & -1.1 & 1.7 & 10.3 \\
1987 & 37.6 & 62.4 & -5.3 & 20.9 & 38.8 & 19.4 & 41.8 & -0.8 & 2.5 & 14.0 \\
1989 & 33.8 & 66.2 & -4.2 & 29.2 & 36.8 & 20.2 & 43.1 & 2.3 & 3.7 & 19.0 \\
1991 & 32.9 & 67.1 & -5.9 & 28.9 & 36.4 & 21.3 & 42.3 & 0.8 & 3.9 & 18.4 \\
1993 & 31.8 & 68.2 & -3.6 & 27.3 & 35.3 & 22.4 & 42.3 & 2.9 & 3.8 & 17.0 \\
1995 & 38.3 & 61.7 & -5.2 & 15.0 & 39.6 & 23.4 & 37.0 & -1.4 & 2.2 & 9.1 \\
1997 & 36.9 & 63.1 & -2.3 & 18.7 & 38.5 & 24.2 & 37.3 & 2.5 & 2.8 & 11.1 \\
1999 & 36.5 & 63.5 & 2.0 & 21.0 & 38.3 & 24.8 & 36.8 & 7.4 & 3.3 & 12.2 \\
\hline
\end{tabular}

Table 3: Contributions to the observed gender wage gap (\%). Source: Computations based on Portugal, MSST (1985 to 1999).

The decomposition based on the Cotton-Neumark methodology reveals that, for the group of all the variables, differences in endowments, the male advantage and the female disadvantage contribute positively to the observed gender gap, which is in line with the results of Gyimah-Brempong et al (1992). The contribution of the female disadvantage is larger than the contribution of the male advantage.

With respect to the proportion of females in the establishment, most of the observed gender gap is due to the female disadvantage component, rather than to the male advantage or to differences in endowments, whose contributions to the gap are fairly low. Indeed, female underpayment accounts for 10 percent to 19 percent of the gender pay gap, whereas male overpayment accounts for 2 percent to 4 percent of that gap. This finding is at odds with the results of Rilley and Wirjanto (1999), who found a negative contribution of the female disadvantage, suggesting that the impact of the femaleness of the establishment on the observed gender wage gap operated mainly through males' wage advantage.

We have compared the contribution of the variable share of females to the total wage gap with the contribution of industries or occupations. The contribution of occupations taken together or industries taken together to the total gender wage gap is dwarfed by the much larger contribution of the variable share of females. ${ }^{9}$

Table 10 in appendix reports the decompositions of the wage gap using fixed-effects estimation. Once we account for unobserved heterogeneity across firms, the contribution of the share of females to the total wage gap is, as expected, substantially lower (1 percent to 15 percent contribution when using fixed-effects, instead of 10 percent to 25 percent with OLS). However, a remarkable rising trend can still be detected, from a 3 percent contribution in

${ }^{9}$ The share of females accounts for 10 percent to 25 percent of the gap, whereas occupations account for -2 percent to 8 percent, and industries account for -8 percent to 0 percent; the only exception is 1985, when the contribution of occupations taken together reaches 19 percent. 
1985 to 15 percent in 1999. The endowments component still exerts an egalitarian impact on the wage distribution (i.e. a negative contribution to the gender wage gap), showing now a larger magnitude. Therefore, prices continue to be the major force driving the contribution of the variable share of females to the gender wage gap.

In synthesis, for the Portuguese case, segregation remained at stable levels from 1985 to 1999, but nevertheless the degree of femaleness of the establishment tended to become more relevant accounting for wage differences across gender.

The question that would follow is of course what has driven these changes in prices, but at this stage one can only present some speculative reasoning. During the second half of the 80s the Portuguese economy grew at a very fast pace. A large share of low-paid females in an establishment might have resulted in a larger pie to be distributed among males, in a rent-dissipation argument similar to the one presented by Winter-Ebmer and Zweimüller (1996). Economic growth combined with short supply of qualified labor has indeed led until mid-90s to rising wage dispersion, with the bottom wages growing slowly, when compared to top wages, which increased very sharply.

An alternative explanation may be derived from Goldin (1990), who analyzed specifically the rising female labor force participation and the gender gap in the USA. On several fronts, the evidence on Portugal is consistent with Goldin's reasoning. ${ }^{10}$ She shows that recent entrants to the labor market tend to be older women, with less labor market experience than the women already in the labor market. The decline in average actual experience would lead to a decline in average females wages and an increase in the gender gap, particularly if one controls for potential experience and not for actual experience. In Portugal, the average age of employed females indeed increased, from 33.6 years in 1985 to 34.9 in 1999. Also, the gender wage gap, as captured in wage regressions using potential labor market experience, increased up to the early nineties. Progressing in this reasoning, if the women entering the labor market tend to work mainly in establishments that were already employing a high proportion of females, which occurred in Portugal, then segregation would account for an increasing proportion of the wage gap. Furthermore, potential experience contains more error as older women and actually less experienced ones join the labor force, such that the increasing role of segregation would show up as a rising 'price effect'. Evidence on Portugal is also consistent with this piece of the reasoning. In synthesis, rising participation of females from slightly older groups may provide several clues to explain the pattern and trends in the gender pay gap detected in Portugal.

\section{Conclusion}

This paper analyzed gender segregation at the establishment level over fifteen years in Portugal, and its impact on wages and the gender wage gap. A large employer-employee matched data set has been used.

Results point to a high level of systematic gender segregation at the establishment level. A higher proportion of females in the establishment lowers females' wages and, on the contrary, it raises males' wages. The latter outcome contrasts with the evidence available for other countries. Such evidence lends support to wage discrimination type of models. However, comparison of the results obtained using OLS and including firm-specific fixed-effects in the regressions highlights the relevance of sorting of workers into establishments, based on their productivity, to the explanation of the pattern and trend in gender wage setting in Portugal. Similarly, it highlights that discrimination mechanisms are declining over time. The results

\footnotetext{
${ }^{10}$ We are grateful to one of the referees for having drawn our attention to this point.
} 
point to the relevance of taking into account gender segregation of the workforce at the establishment level when analyzing the gender wage gap and deciding on policy measures.

\section{References}

Bayard, Kimberly, Judith Hellerstein, David Neumark and Kenneth Troske (2003). New evidence on sex segregation and sex differences in wages from matched employer-employee data, Journal of Labor Economics, 21(4), 887-922.

Becker, Gary S. (1971). The Economics of Discrimination. Chicago: University of Chicago Press.

Boisso, Dale, Kathy Hayes, Joseph Hirschberg and Jacques Silber (1994). Occupational segregation in the multidimensional case, Journal of Econometrics, 61, 161171.

Branco, Fernando and António Mello (1992). Why are wages in Portugal lower than elsewhere in EEC? in J. Amaral and D. Lucena (eds.) The Portuguese Economy Towards 1992. Boston: Kluwer, 131-151.

Buckley, John E. (1971). Pay differences between men and women in the same job, Monthly Labor Review, 64(11), 36-39.

Cardoso, Ana Rute (1998). Earnings inequality in Portugal: High and rising? Review of Income and Wealth, 44(3), 325-343.

Cardoso, Ana Rute and Pedro Portugal (2005). Contractual wages and the wage cushion under different bargaining settings. Journal of Labor Economics, forthcoming.

Carrington, William J. and Kenneth R. Troske (1995). Gender segregation in small firms, Journal of Human Resources, 30(3), 503-533.

Carrington, William J. and Kenneth R. Troske (1997). On measuring segregation in samples with small units, Journal of Business and Economic Statistics, 15(4), 402409.

Carrington, William J. and Kenneth R. Troske (1998). Sex segregation in the U.S. manufacturing, Industrial and Labor Relations Review, 51(3), 445-464.

Cotton, Jeremiah (1988). On the decomposition of wage differentials, Review of Economics and Statistics, 70(2), 236-243.

FlüCkiger, Yves And Jacques Silber (1999). The Measurement of Segregation in the Labor Force. Heidelberg: Physica-Verlag.

Goldin, Claudia (1990). Understanding the Gender Gap. Oxford: Oxford University Press.

Groshen , Erica L. (1991). The structure of the female/male wage differential: is it who you are, what you do, or where you work? Journal of Human Resources, 26 (3), 457-472.

Gyimah-Brempong, Kwabena, Rudy Fichtenbaum and Gregory Willis (1992) The effects of College education on the male-female wage differential, Southern Economic Journal, 58(3), 790-804. 
Hartog, Joop, Pedro Pereira And José Vieira (2000). Inter-industry wage dispersion in Portugal, Empirica, 27, 353-364.

Hartog, Joop, Pedro Pereira and José Vieira (2001). Changing returns to education in Portugal during the 1980s and the early 1990s: OLS and quantile regression analysis, Applied Economics, 33, 1021-1037.

Hutchens, Robert (1991). Segregation curves, Lorenz curves, and inequality in the distribution of people across occupations, Mathematical Social Sciences, 21, 31-51.

Hutchens, Robert (2001). Numerical measures of segregation: desirable properties and their implications, Mathematical Social Sciences, 42(1), 13-29.

Kremer, Michael (1993). The O-ring theory of economic development, Quarterly Journal of Economics, 108(3), 551-575.

Kremer, Michael AND ERIC MAskin (1996). Wage inequality and segregation by skill, NBER working paper 5718. Cambridge, MA: National Bureau of Economic Research.

Kiker, B. F. And Maria C. Santos (1991). Human capital and earnings in Portugal, Economics of Education Review, 10(3), 187-203.

McNulty, Donald J. (1967). Differences in pay between men and women workers, Monthly Labor Review, 90(12), 40-43.

Neumark, David (1988). Employers' discriminatory behavior and the estimation of wage discrimination, Journal of Human Resources, 23(3), 279-295.

OAxaca, Ronald L. (1973). Male-female wage differentials in urban labor markets, International Economic Review, 14, 693-709.

OECD [Organization for Economic Co-operation and Development) (1994). Economic Surveys, Portugal, 1993-1994. OECD: Paris.

Pfeffer, Jeffrey and Alison Davis-Blake (1987). The effect of the proportion of women on salaries: the case of College administrators, Industrial and Labor Relations Review, 31(1), 1-24.

Portugal. Ministério da Segurança Social e do Trabalho (1985-1999). Quadros de Pessoal. Data in magnetic media.

Reilly, Kevin T. and Tony S. Wirjanto (1999). Does more mean less? The male/female wage gap and the proportion of females at the establishment level, Canadian Journal of Economics, 32(4), 906-929.

Vieira, José A. Cabral (1999). The evolution of wage structures in Portugal 1982-1992, Ph.D. Thesis, Amsterdam: Tinbergen Institute.

Winter-Ebmer, Rudolf and Josef Zweimüller (1996). Immigration and the earnings of young native workers, Oxford Economic Papers, 48(3), 473-491.

Yoon, Soohyun, Kenneth R. Troske and Peter Mueser (2003). Changes in gender segregation and women's wages in Korea. Mimeo. University of Missouri-Columbia. 
Appendix: additional tables 


\begin{tabular}{|c|c|c|c|c|c|c|c|c|}
\hline & 1985 & 1987 & 1989 & 1991 & 1993 & 1995 & 1997 & 1999 \\
\hline Ln hourly wage & 5.2596 & 5.5933 & 5.8110 & 6.1595 & 6.3603 & 6.4971 & 6.5818 & 6.7216 \\
\hline Proportion of females & 0.1997 & 0.2052 & 0.2145 & 0.2228 & 0.2295 & 0.2363 & 0.2404 & 0.2463 \\
\hline Education & 5.5132 & 5.6484 & 5.9063 & 6.1435 & 6.3539 & 6.6805 & 7.0088 & 7.3542 \\
\hline Experience $(*)$ & 26.208 & 26.127 & 25.507 & 25.387 & 25.294 & 24.810 & 24.298 & 24.204 \\
\hline Experience squared(*) & 848.27 & 840.94 & 810.48 & 807.32 & 801.6 & 777.17 & 756.13 & 753.48 \\
\hline Tenure & 10.006 & 10.1162 & 9.4890 & 9.2806 & 9.1149 & 8.9454 & 8.5275 & 8.4567 \\
\hline Tenure squared & 178.10 & 183.91 & 175.58 & 175.83 & 170.14 & 165.72 & 158.41 & 158.44 \\
\hline Ln establishment size & 4.6677 & 4.5950 & 4.4681 & 4.3857 & 4.2385 & 4.0938 & 4.0590 & 4.0027 \\
\hline Lisbon & 0.4251 & 0.4103 & 0.4007 & 0.3997 & 0.3948 & 0.3805 & 0.3798 & 0.3804 \\
\hline Occupations: & & & & & & & & \\
\hline Managers, higher clericals & 0.0111 & 0.0103 & 0.0113 & 0.0119 & 0.0113 & 0.0311 & 0.0357 & 0.0401 \\
\hline Clerical staff & 0.0895 & 0.0883 & 0.0936 & 0.0982 & 0.1007 & 0.1161 & 0.1152 & 0.1269 \\
\hline Commercial staff & 0.1357 & 0.1329 & 0.1274 & 0.1248 & 0.1244 & 0.1329 & 0.1248 & 0.1231 \\
\hline Security and other services & 0.0585 & 0.0588 & 0.056 & 0.0568 & 0.0586 & 0.0701 & 0.0715 & 0.0697 \\
\hline Farmers, agricult. workers & 0.0024 & 0.002 & 0.0026 & 0.0023 & 0.0021 & 0.0029 & 0.0035 & 0.0033 \\
\hline Production workers (group 1) & 0.2931 & 0.2892 & 0.2861 & 0.2921 & 0.2868 & 0.2933 & 0.2953 & 0.2923 \\
\hline Production workers (group 2) & 0.1738 & 0.1718 & 0.1629 & 0.1651 & 0.1603 & 0.1793 & 0.1812 & 0.1759 \\
\hline Production workers (group 3) & 0.2118 & 0.2215 & 0.2353 & 0.2201 & 0.2286 & 0.1367 & 0.1363 & 0.1336 \\
\hline Industries: & & & & & & & & \\
\hline Textiles, clothing, footwear & 0.0919 & 0.0949 & 0.0938 & 0.0898 & 0.0848 & 0.083 & 0.078 & 0.0708 \\
\hline Wood, cork & 0.0461 & 0.046 & 0.0448 & 0.0408 & 0.0407 & 0.0476 & 0.0465 & 0.0441 \\
\hline Paper, print, publish. & 0.0272 & 0.0271 & 0.0266 & 0.0263 & 0.0249 & 0.0251 & 0.0238 & 0.023 \\
\hline Chemical products & 0.0480 & 0.0468 & 0.0438 & 0.0368 & 0.0346 & 0.0285 & 0.0255 & 0.0262 \\
\hline Non-metal minerals & 0.0430 & 0.0406 & 0.0387 & 0.0398 & 0.0382 & 0.0346 & 0.0325 & 0.0336 \\
\hline Primary metals & 0.0210 & 0.0203 & 0.0176 & 0.0144 & 0.013 & 0.0088 & 0.0081 & 0.0077 \\
\hline Machinery, equipment & 0.1315 & 0.1239 & 0.124 & 0.1176 & 0.119 & 0.1075 & 0.1125 & 0.1102 \\
\hline Elect., gas, water & 0.0214 & 0.0214 & 0.0157 & 0.0181 & 0.0173 & 0.0168 & 0.0161 & 0.0141 \\
\hline Construction & 0.1247 & 0.1257 & 0.1363 & 0.1449 & 0.1488 & 0.1574 & 0.1665 & 0.1634 \\
\hline Wholesale & 0.0903 & 0.0904 & 0.0893 & 0.0924 & 0.0922 & 0.0865 & 0.0835 & 0.0847 \\
\hline Retail & 0.0474 & 0.0491 & 0.054 & 0.0563 & 0.0592 & 0.0874 & 0.0884 & 0.0902 \\
\hline Rest., cafes, hotels & 0.0309 & 0.0321 & 0.0332 & 0.0336 & 0.0351 & 0.0399 & 0.0389 & 0.0387 \\
\hline Transportation & 0.1083 & 0.1117 & 0.1014 & 0.1096 & 0.106 & 0.1002 & 0.0971 & 0.0982 \\
\hline Banking, insurance & 0.0555 & 0.0541 & 0.0601 & 0.0584 & 0.0601 & 0.0595 & 0.0523 & 0.0484 \\
\hline Services to firms & 0.0176 & 0.0182 & 0.0219 & 0.0261 & 0.0282 & 0.0045 & 0.0048 & 0.0056 \\
\hline Social, personal serv. & 0.0440 & 0.0463 & 0.0484 & 0.0480 & 0.0506 & 0.0675 & 0.0832 & 0.1008 \\
\hline
\end{tabular}

Table 4: Sample mean values (males). Note: $(*)$ Potential experience, computed as age-education-6. Source: Computations based on Portugal, MSST (1985 to 1999). 


\begin{tabular}{|c|c|c|c|c|c|c|c|c|}
\hline & 1985 & 1987 & 1989 & 1991 & 1993 & 1995 & 1997 & 1999 \\
\hline Ln hourly wage & 5.0022 & 5.3423 & 5.5412 & 5.8701 & 6.0735 & 6.2327 & 6.3260 & 6.4631 \\
\hline Proportion of females & 0.5639 & 0.5767 & 0.5956 & 0.6082 & 0.6185 & 0.6341 & 0.6455 & 0.6505 \\
\hline Education & 5.4763 & 5.7060 & 6.0359 & 6.3121 & 6.5439 & 7.0174 & 7.3776 & 7.7936 \\
\hline Experience $(*)$ & 22.168 & 22.272 & 21.626 & 21.267 & 21.240 & 21.278 & 21.125 & 21.118 \\
\hline Experience squared $(*)$ & 627.35 & 631.66 & 603.7 & 588.88 & 588.39 & 592.58 & 592.64 & 597.43 \\
\hline Tenure & 8.9576 & 9.0402 & 8.3458 & 7.8066 & 7.5880 & 7.7406 & 7.4244 & 7.2951 \\
\hline Tenure squared & 136.07 & 143.12 & 135.83 & 129.95 & 124.24 & 127.21 & 123.15 & 122.81 \\
\hline Ln establishment size & 4.6199 & 4.5449 & 4.4241 & 4.3596 & 4.2646 & 4.1835 & 4.1423 & 4.1082 \\
\hline Lisbon & 0.4018 & 0.3948 & 0.3790 & 0.3733 & 0.3709 & 0.3621 & 0.3588 & 0.3702 \\
\hline Occupations: & & & & & & & & \\
\hline Managers, higher clericals & 0.0127 & 0.0139 & 0.0166 & 0.0171 & 0.0202 & 0.0305 & 0.0351 & 0.0405 \\
\hline Clerical staff & 0.0677 & 0.0704 & 0.0742 & 0.0793 & 0.0814 & 0.0718 & 0.0721 & 0.0814 \\
\hline Commercial staff & 0.2124 & 0.2019 & 0.1968 & 0.1894 & 0.1852 & 0.2145 & 0.2067 & 0.2125 \\
\hline Security and other services & 0.0768 & 0.0817 & 0.0825 & 0.0861 & 0.0967 & 0.1400 & 0.1624 & 0.1713 \\
\hline Farmers, agricult. workers & 0.0016 & 0.0012 & 0.0023 & 0.0018 & 0.0014 & 0.0016 & 0.0021 & 0.0018 \\
\hline Production workers (group 1) & 0.2469 & 0.2506 & 0.2541 & 0.2649 & 0.2512 & 0.2427 & 0.2388 & 0.2219 \\
\hline Production workers (group 2) & 0.1249 & 0.1143 & 0.0954 & 0.0812 & 0.0707 & 0.0943 & 0.0797 & 0.0697 \\
\hline Production workers (group 3) & 0.2507 & 0.2575 & 0.2681 & 0.2685 & 0.2824 & 0.1886 & 0.1871 & 0.1848 \\
\hline Industries: & & & & & & & & \\
\hline Textiles, clothing, footwear & 0.3288 & 0.3287 & 0.3279 & 0.3210 & 0.3017 & 0.2858 & 0.2633 & 0.2366 \\
\hline Wood, cork & 0.027 & 0.0248 & 0.0234 & 0.0224 & 0.0222 & 0.0261 & 0.0258 & 0.0252 \\
\hline Paper, print, publish. & 0.0216 & 0.0217 & 0.02 & 0.018 & 0.0172 & 0.0178 & 0.0159 & 0.0157 \\
\hline Chemical products & 0.0396 & 0.0363 & 0.0318 & 0.0275 & 0.0248 & 0.0198 & 0.0167 & 0.0177 \\
\hline Non-metal minerals & 0.0248 & 0.0233 & 0.0222 & 0.0245 & 0.024 & 0.0238 & 0.0223 & 0.0226 \\
\hline Primary metals & 0.0049 & 0.0041 & 0.0035 & 0.0028 & 0.0024 & 0.0016 & 0.0014 & 0.0016 \\
\hline Machinery, equipment & 0.0689 & 0.0657 & 0.0600 & 0.0633 & 0.0627 & 0.0674 & 0.0684 & 0.0716 \\
\hline Elect., gas, water & 0.0068 & 0.0069 & 0.0045 & 0.0050 & 0.0046 & 0.0042 & 0.0043 & 0.0037 \\
\hline Construction & 0.0129 & 0.0117 & 0.0141 & 0.0161 & 0.0162 & 0.0157 & 0.0167 & 0.0171 \\
\hline Wholesale & 0.0687 & 0.0654 & 0.0643 & 0.0648 & 0.0647 & 0.0594 & 0.0579 & 0.0587 \\
\hline Retail & 0.0627 & 0.0651 & 0.0679 & 0.0716 & 0.0785 & 0.0948 & 0.1043 & 0.1118 \\
\hline Rest., cafes, hotels & 0.0534 & 0.0542 & 0.0563 & 0.0574 & 0.063 & 0.0715 & 0.0710 & 0.0684 \\
\hline Transportation & 0.0585 & 0.0582 & 0.0534 & 0.0524 & 0.0489 & 0.0433 & 0.0407 & 0.0388 \\
\hline Banking, insurance & 0.0421 & 0.0402 & 0.0447 & 0.0419 & 0.0436 & 0.0440 & 0.0396 & 0.0398 \\
\hline Services to firms & 0.0139 & 0.0162 & 0.0210 & 0.0256 & 0.0284 & 0.0046 & 0.0048 & 0.0056 \\
\hline Social, personal serv. & 0.0916 & 0.1112 & 0.1238 & 0.1275 & 0.1441 & 0.1683 & 0.1984 & 0.2217 \\
\hline
\end{tabular}

Table 5: Sample mean values (females). Note: $(*)$ Potential experience, computed as age-education-6. Source: Computations based on Portugal, MSST (1985 to 1999). 


\begin{tabular}{|c|c|c|c|c|c|c|c|c|}
\hline & \multicolumn{2}{|c|}{1985} & \multicolumn{2}{|c|}{1987} & \multicolumn{2}{|c|}{1989} & \multicolumn{2}{|c|}{1991} \\
\hline & coeff. & t-value & coeff. & t-value & coeff. & t-value & coeff. & t-value \\
\hline Proportion of females & 0.0296 & 13.7 & 0.0356 & 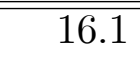 & 0.0297 & 13.2 & 0.0441 & 18.1 \\
\hline Education & 0.0506 & 290.6 & 0.0552 & 305.2 & 0.0623 & 331.8 & 0.0656 & 328.1 \\
\hline Experience & 0.0268 & 197.6 & 0.0287 & 204.3 & 0.0296 & 207.3 & 0.0281 & 182.3 \\
\hline Experience sq./100 & -0.0353 & -162.0 & -0.0374 & -165.0 & -0.0383 & -164.0 & -0.0362 & -142.6 \\
\hline Tenure/10 & 0.1036 & 86.4 & 0.1047 & 85.5 & 0.1033 & 81.0 & 0.0982 & 68.8 \\
\hline Tenure squared/100 & -0.0129 & -36.3 & -0.0122 & -33.3 & -0.0118 & -30.0 & -0.0103 & -23.3 \\
\hline Ln establishment size & 0.0575 & 245.2 & 0.0604 & 250.2 & 0.0551 & 216.9 & 0.0543 & 188.4 \\
\hline Region: Lisbon & 0.0726 & 98.2 & 0.0686 & 89.4 & 0.0763 & 93.7 & 0.0985 & 109.9 \\
\hline Intercept & 4.4763 & 1010.9 & 4.7145 & 1056.4 & 4.9234 & 1042.7 & 5.3015 & 1066.8 \\
\hline Occupation (9 categories) & yes & yes & yes & yes & yes & yes & yes & yes \\
\hline Industry (17 categories) & yes & yes & yes & yes & yes & yes & yes & yes \\
\hline Observ. & 862137 & & 860395 & & 889362 & & 885135 & \\
\hline Adjusted R2 & 0.6234 & & 0.6373 & & 0.5995 & & 0.5596 & \\
\hline
\end{tabular}

\begin{tabular}{|c|c|c|c|c|c|c|c|c|}
\hline & \multicolumn{2}{|c|}{1993} & \multicolumn{2}{|c|}{1995} & \multicolumn{2}{|c|}{1997} & \multicolumn{2}{|c|}{1999} \\
\hline & coeff. & t-value & coeff. & t-value & coeff. & t-value & coeff. & t-value \\
\hline Proportion of females & 0.0262 & 10.4 & 0.0344 & 14.7 & 0.0147 & 6.6 & -0.0127 & -6.4 \\
\hline Education & 0.0682 & 331.8 & 0.0474 & 216.9 & 0.0456 & 223.3 & 0.0459 & 243.8 \\
\hline Experience & 0.0279 & 172.7 & 0.0272 & 176.1 & 0.0269 & 182.8 & 0.0254 & 193.0 \\
\hline Experience sq./100 & -0.0350 & -130.6 & -0.0363 & -141.1 & -0.0357 & -143.7 & -0.0336 & -151.5 \\
\hline Tenure/10 & 0.1015 & 64.6 & 0.1052 & 67.9 & 0.1304 & 89.0 & 0.1420 & 105.2 \\
\hline Tenure squared/100 & -0.0134 & -27.3 & -0.0125 & -25.8 & -0.0188 & -41.2 & -0.0203 & -48.1 \\
\hline Ln establishment size & 0.0554 & 185.4 & 0.0570 & 191.8 & 0.0584 & 212.7 & 0.0569 & 215.4 \\
\hline Region: Lisbon & 0.1104 & 116.3 & 0.1037 & 112.3 & 0.0923 & 102.8 & 0.0934 & 112.8 \\
\hline Intercept & 5.4926 & 1058.2 & 5.9543 & 1088.1 & 6.0823 & 1139.7 & 6.2650 & 1220.0 \\
\hline Occupation (9 categories) & yes & yes & yes & yes & yes & yes & yes & yes \\
\hline Industry (17 categories) & yes & yes & yes & yes & yes & yes & yes & yes \\
\hline Observ. & 868326 & & 859522 & & 923256 & & 947059 & \\
\hline Adjusted R2 & 0.5444 & & 0.6041 & & 0.5951 & & 0.6343 & \\
\hline
\end{tabular}

Table 6: Ordinary least squares regressions (males). Source: Computations based on Portugal, MSST (1985 to 1999). 


\begin{tabular}{|c|c|c|c|c|c|c|c|c|}
\hline & \multicolumn{2}{|c|}{1985} & \multicolumn{2}{|c|}{1987} & \multicolumn{2}{|c|}{1989} & \multicolumn{2}{|c|}{1991} \\
\hline & coeff. & t-value & coeff. & t-value & coeff. & t-value & coeff. & t-value \\
\hline Proportion of females & -0.0393 & -17.6 & -0.0552 & -24.3 & -0.1027 & -45.1 & -0.0936 & -38.6 \\
\hline Education & 0.0475 & 178.1 & 0.0564 & 203.0 & 0.0610 & 229.3 & 0.0662 & 235.6 \\
\hline Experience & 0.0155 & 81.8 & 0.0166 & 87.7 & 0.0175 & 99.5 & 0.0161 & 89.4 \\
\hline Experience sq./100 & -0.0192 & -59.6 & -0.0199 & -61.7 & -0.0202 & -65.2 & -0.0180 & -54.8 \\
\hline Tenure/10 & 0.1209 & 72.0 & 0.1213 & 72.8 & 0.1186 & 71.3 & 0.1169 & 64.8 \\
\hline Tenure squared/100 & -0.0216 & -38.8 & -0.0199 & -35.5 & -0.0195 & -32.0 & -0.0173 & -26.2 \\
\hline Ln establishment size & 0.0458 & 138.6 & 0.0486 & 147.3 & 0.0444 & 133.3 & 0.0443 & 126.4 \\
\hline Region: Lisbon & 0.0764 & 70.4 & 0.0679 & 62.3 & 0.0660 & 61.0 & 0.0795 & 69.4 \\
\hline Intercept & 4.5373 & 517.8 & 4.7177 & 598.4 & 4.9534 & 642.1 & 5.2926 & 701.9 \\
\hline Occupation (9 categories) & yes & yes & yes & yes & yes & yes & yes & yes \\
\hline Industry (17 categories) & yes & yes & yes & yes & yes & yes & yes & yes \\
\hline Observ. & 402523 & & 424697 & & 477440 & & 507748 & \\
\hline Adjusted R2 & 0.6594 & & 0.6498 & & 0.6355 & & 0.5864 & \\
\hline
\end{tabular}

\begin{tabular}{|c|c|c|c|c|c|c|c|c|}
\hline & \multicolumn{2}{|c|}{1993} & \multicolumn{2}{|c|}{1995} & \multicolumn{2}{|c|}{1997} & \multicolumn{2}{|c|}{1999} \\
\hline & coeff. & t-value & coeff. & t-value & coeff. & t-value & coeff. & t-value \\
\hline Proportion of females & -0.1003 & -38.7 & -0.0283 & -12.0 & -0.0596 & -26.8 & -0.0960 & -50.7 \\
\hline Education & 0.0710 & 246.4 & 0.0434 & 170.1 & 0.0411 & 177.0 & 0.0423 & 213.5 \\
\hline Experience & 0.0166 & 87.2 & 0.0176 & 98.3 & 0.0183 & 109.6 & 0.0169 & 126.2 \\
\hline Experience sq./100 & -0.0182 & -52.2 & -0.0228 & -68.3 & -0.0243 & -78.6 & -0.0215 & -88.8 \\
\hline Tenure/10 & 0.1297 & 63.3 & 0.1284 & 67.8 & 0.1368 & 79.6 & 0.1482 & 105.2 \\
\hline Tenure squared/100 & -0.0228 & -30.9 & -0.0221 & -33.5 & -0.0236 & -39.9 & -0.0254 & -52.7 \\
\hline Ln establishment size & 0.0473 & 135.3 & 0.0548 & 164.7 & 0.0532 & 174.7 & 0.0440 & 172.4 \\
\hline Region: Lisbon & 0.0927 & 75.8 & 0.0769 & 68.4 & 0.0715 & 66.8 & 0.0637 & 72.5 \\
\hline Intercept & 5.4427 & 675.2 & 5.8800 & 756.4 & 6.0455 & 834.8 & 6.2469 & 931.2 \\
\hline Occupation(9 categories) & yes & yes & yes & yes & yes & yes & yes & yes \\
\hline Industry (17 categories) & yes & yes & yes & yes & yes & yes & yes & yes \\
\hline Observ. & 524732 & & 562909 & & 634009 & & 675553 & \\
\hline Adjusted R2 & 0.5631 & & 0.6317 & & 0.6118 & & 0.6833 & \\
\hline
\end{tabular}

Table 7: Ordinary least squares Regressions (Females). Source: Computations based on Portugal, MSST (1985 to 1999). 


\begin{tabular}{|c|c|c|c|c|c|c|c|c|}
\hline & \multicolumn{2}{|c|}{1985} & \multicolumn{2}{|c|}{1987} & \multicolumn{2}{|c|}{1989} & \multicolumn{2}{|c|}{1991} \\
\hline & coeff. & t-value & coeff. & t-value & coeff. & t-value & coeff. & t-value \\
\hline Proportion of females & 0.1169 & 24.2 & 0.0771 & 15.5 & 0.0839 & 15.7 & 0.1065 & 18.3 \\
\hline Education & 0.0397 & 248.6 & 0.0422 & 255.9 & 0.0478 & 272.4 & 0.0499 & 265.8 \\
\hline Experience & 0.0229 & 205.6 & 0.0243 & 205.1 & 0.0264 & 212.1 & 0.0257 & 189.1 \\
\hline Experience sq./100 & -0.0300 & -176.0 & -0.0300 & -170.4 & -0.0300 & -173.3 & -0.0300 & -152.1 \\
\hline Tenure/10 & 0.0920 & 85.4 & 0.0880 & 78.5 & 0.0850 & 70.1 & 0.0810 & 58.8 \\
\hline Tenure squared/100 & -0.0100 & -26.3 & -0.0100 & -21.2 & -0.0100 & -14.5 & 0.0000 & -10.1 \\
\hline Ln establishment size & -0.0023 & -6.1 & 0.0012 & 3.0 & -0.0009 & -2.0 & 0.0014 & 2.9 \\
\hline Region: Lisbon & 0.0129 & 11.8 & 0.0183 & 16.1 & 0.0274 & 21.4 & 0.0304 & 21.3 \\
\hline Intercept & 3.9703 & & 3.8010 & & 5.4307 & 360.7 & 5.7564 & 525.7 \\
\hline Occupation(9 categories) & yes & & yes & & yes & & yes & \\
\hline Industry (17 categories) & yes & & yes & & yes & & yes & \\
\hline Observ. & & 862137 & & 860395 & & 889362 & & 885135 \\
\hline Adjusted R2 & & 0.800 & & 0.800 & & 0.770 & & 0.730 \\
\hline
\end{tabular}

\begin{tabular}{|c|c|c|c|c|c|c|c|c|}
\hline & \multicolumn{2}{|c|}{1993} & \multicolumn{2}{|c|}{1995} & \multicolumn{2}{|c|}{1997} & \multicolumn{2}{|c|}{1999} \\
\hline & coeff. & t-value & coeff. & t-value & coeff. & t-value & coeff. & t-value \\
\hline Proportion of females & 0.0633 & 10.1 & 0.0299 & 5.1 & 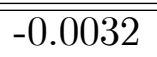 & $\begin{array}{ll}-0.6 \\
\end{array}$ & 0.0095 & 101.9 \\
\hline Education & 0.0523 & 266.1 & 0.0350 & 177.7 & 0.0342 & 185.5 & 0.0350 & 207.2 \\
\hline Experience & 0.0261 & 181.3 & 0.0244 & 177.6 & 0.0247 & 191.1 & 0.0237 & 208.1 \\
\hline Experience sq./100 & -0.0300 & -141.0 & -0.0300 & -143.1 & -0.0300 & -151.4 & -0.0300 & -165.1 \\
\hline Tenure/10 & 0.0850 & 56.1 & 0.0930 & 61.4 & 0.1120 & 78.5 & 0.1170 & 90.5 \\
\hline Tenure squared/100 & -0.0100 & -13.4 & -0.0100 & -20.1 & -0.0100 & -32.8 & -0.0100 & -37.8 \\
\hline Ln establishment size & 0.0038 & 7.2 & -0.0005 & -1.0 & 0.0021 & 4.2 & 0.0048 & 9.1 \\
\hline Region: Lisbon & 0.0339 & 22.3 & 0.0417 & 26.7 & 0.0383 & 26.5 & 0.0350 & 25.2 \\
\hline Intercept & 5.9339 & 432.8 & 6.5338 & 432.8 & 6.5587 & 413.3 & 10.8324 & 0.0 \\
\hline Occupation(9 categories) & yes & & yes & & yes & & yes & \\
\hline Industry (17 categories) & yes & & yes & & yes & & yes & \\
\hline Observ. & & 868326 & & 859522 & & 923256 & & 947059 \\
\hline Adjusted R2 & & 0.710 & & 0.760 & & 0.760 & & 0.790 \\
\hline
\end{tabular}

Table 8: Firm fixed-effects Regressions (males). Source: Computations based on Portugal, MSST (1985 to 1999). 


\begin{tabular}{|c|c|c|c|c|c|c|c|c|}
\hline & \multicolumn{2}{|c|}{1985} & \multicolumn{2}{|c|}{1987} & \multicolumn{2}{|c|}{1989} & \multicolumn{2}{|c|}{1991} \\
\hline & coeff. & t-value & coeff. & t-value & coeff. & t-value & coeff. & t-value \\
\hline Proportion of females & 0.0290 & 5.1 & 0.0232 & 3.8 & 0.0171 & 2.6 & 0.0153 & 202.2 \\
\hline Education & 0.0346 & 146.9 & 0.0401 & 170.7 & 0.0454 & 188.3 & 0.0499 & 195.6 \\
\hline Experience & 0.0116 & 73.8 & 0.0128 & 80.1 & 0.0143 & 92.8 & 0.0136 & 84.2 \\
\hline Experience sq./100 & -0.0100 & -56.7 & -0.0200 & -59.9 & -0.0200 & -65.1 & -0.0200 & -54.7 \\
\hline Tenure/10 & 0.1080 & 65.1 & 0.1110 & 67.1 & 0.1060 & 63.6 & 0.1100 & 60.6 \\
\hline Tenure squared/100 & -0.0200 & -32.1 & -0.0200 & -30.8 & -0.0100 & -24.5 & -0.0100 & -23.2 \\
\hline Ln establishment size & 0.0040 & 5.9 & 0.0090 & 12.6 & 0.0048 & 7.3 & 0.0121 & 16.7 \\
\hline Region: Lisbon & 0.0241 & 11.5 & 0.0277 & 13.5 & 0.0254 & 11.2 & 0.0335 & 15.1 \\
\hline Intercept & 4.9945 & 441.8 & 5.1845 & 455.0 & 5.3791 & 422.9 & 5.6665 & 405.7 \\
\hline Occupation(9 categories) & yes & & yes & & yes & & yes & \\
\hline Industry (17 categories) & yes & & yes & & yes & & yes & \\
\hline Observ. & & 402523 & & 424697 & & 477440 & & 507480 \\
\hline Adjusted R2 & & 0.823 & & 0.810 & & 0.790 & & 0.740 \\
\hline
\end{tabular}

\begin{tabular}{|c|c|c|c|c|c|c|c|c|}
\hline & \multicolumn{2}{|c|}{1993} & \multicolumn{2}{|c|}{1995} & \multicolumn{2}{|c|}{1997} & \multicolumn{2}{|c|}{1999} \\
\hline & coeff. & t-value & coeff. & t-value & coeff. & t-value & coeff. & t-value \\
\hline Proportion of females & -0.0058 & -0.8 & -0.0275 & -3.9 & -0.0421 & -6.7 & -0.0545 & -10.0 \\
\hline Education & 0.0545 & 206.5 & 0.0316 & 132.5 & 0.0304 & 138.4 & 0.0314 & 171.3 \\
\hline Experience & 0.0143 & 82.4 & 0.0145 & 91.2 & 0.0151 & 101.5 & 0.0146 & 124.6 \\
\hline Experience sq./100 & -0.0200 & -52.3 & -0.0200 & -66.1 & -0.0200 & -75.6 & -0.0200 & -90.1 \\
\hline Tenure/10 & 0.1230 & 59.3 & 0.1270 & 66.1 & 0.1360 & 76.5 & 0.1360 & 96.2 \\
\hline Tenure squared/100 & -0.0200 & -27.5 & -0.0200 & -32.0 & -0.0200 & -38.4 & -0.0200 & -48.0 \\
\hline Ln establishment size & 0.0088 & 11.4 & -0.0011 & -1.6 & 0.0013 & 1.9 & 0.0055 & 8.9 \\
\hline Region: Lisbon & 0.0375 & 16.3 & 0.0358 & 15.9 & 0.0481 & 23.9 & 0.0310 & 19.0 \\
\hline Intercept & 5.8422 & 359.6 & 6.4273 & 355.8 & 6.5458 & 360.5 & 6.6773 & 488.1 \\
\hline Occupation(9 categories) & yes & & yes & & yes & & yes & \\
\hline Industry (17 categories) & yes & & yes & & yes & & yes & \\
\hline Observ. & & 524732 & & 562909 & & 634009 & & 675553 \\
\hline Adjusted R2 & & 0.710 & & 0.770 & & 0.750 & & 0.820 \\
\hline
\end{tabular}

Table 9: Firm fiXed-effects Regressions (females). Source: Computations based on Portugal, MSST (1985 to 1999). 
Oaxaca or Cotton-Neumark decomposition (total component)

\begin{tabular}{|c|c|c|c|c|c|c|c|c|}
\hline & 1985 & 1987 & 1989 & 1991 & 1993 & 1995 & 1997 & 1999 \\
\hline OLS & 10.9 & 15.6 & 25.0 & 23.1 & 23.7 & 9.9 & 16.4 & 23.0 \\
\hline fixed effects & 2.7 & 1.0 & 2.9 & 5.0 & 6.3 & 9.3 & 10.3 & 14.6 \\
\hline \multicolumn{9}{|c|}{ Oaxaca decomposition (endowments component) } \\
\hline & 1985 & 1987 & 1989 & 1991 & 1993 & 1995 & 1997 & 1999 \\
\hline OLS & -4.2 & -5.3 & -4.2 & -5.9 & -3.6 & -5.2 & -2.3 & 2.0 \\
\hline fixed effects & -16.5 & -11.4 & -11.9 & -14.2 & -8.6 & -4.5 & 0.5 & -1.5 \\
\hline \multicolumn{9}{|c|}{ Oaxaca decomposition (price component) } \\
\hline & 1985 & 1987 & 1989 & 1991 & 1993 & 1995 & 1997 & 1999 \\
\hline OLS & 15.1 & 20.9 & 29.2 & 28.9 & 27.3 & 15.0 & 18.7 & 21.0 \\
\hline fixed effects & 19.2 & 12.4 & 14.7 & 19.2 & 14.9 & 13.8 & 9.8 & 16.1 \\
\hline
\end{tabular}

Cotton-Neumark decomposition (endowments component)

\begin{tabular}{|l|r|r|r|r|r|r|r|r|}
\hline & 1985 & 1987 & 1989 & 1991 & 1993 & 1995 & 1997 & 1999 \\
\hline OLS & -1.1 & -0.8 & 2.3 & 0.8 & 2.9 & -1.4 & 2.5 & 7.4 \\
fixed effects & -12.6 & -8.8 & -8.6 & -9.8 & -5.1 & -1.1 & 3.0 & 2.7 \\
\hline
\end{tabular}

Cotton-Neumark decomposition (male advantage component)

\begin{tabular}{|l|r|r|r|r|r|r|r|r|}
\hline & 1985 & 1987 & 1989 & 1991 & 1993 & 1995 & 1997 & 1999 \\
\hline OLS & 1.7 & 2.5 & 3.7 & 3.9 & 3.8 & 2.2 & 2.8 & 3.3 \\
fixed effects & 2.2 & 1.5 & 1.9 & 2.6 & 2.1 & 2.0 & 1.5 & 2.5 \\
\hline
\end{tabular}

Cotton-Neumark decomposition (female disadvantage component)

\begin{tabular}{|l|r|r|r|r|r|r|r|r|}
\hline & 1985 & 1987 & 1989 & 1991 & 1993 & 1995 & 1997 & 1999 \\
\hline OLS & 10.3 & 14 & 19 & 18.4 & 17 & 9.1 & 11.1 & 12.2 \\
fixed effects & 13.1 & 8.3 & 9.6 & 12.2 & 9.3 & 8.3 & 5.8 & 9.4 \\
\hline
\end{tabular}

Table 10: Contribution of the share of Females to the total Gender Wage Gap, under alternative estimation methods. Source: Computations based on Portugal, MSST (1985 to 1999). 